\title{
Teaching young adult learners is an intelligent orchestration of science and arts
}

\author{
Rima Namhata \\ Department of Business Administration, Jaipuria Institute of Management, \\ Jaipur, India, and \\ Vinit Ghosh \\ Goa Institute of Management, Sattari, India
}

\section{Teaching young adult learners}

Received 28 July 2020 Revised 7 September 2020 22 September 2020 Accepted 22 September 2020

\begin{abstract}
Purpose - This paper aims to propose a classroom teaching orchestration technique, analogically drawing a reference from the movie, Prestige (2006). The generation of post-millennials has shorter attention span and motivation and prefers a learner-centric teaching style. This paper attempts to mitigate such challenges by bringing an analogy with a magic trick along with proposing a "divergent-convergent diamond structure" to anchor and synthesise teaching deliverables for the learners.

Design/methodology/approach - This is a practitioner's study where practical experiences of the authors have led to the conceptualisation of the central theme discussed.

Findings - From a practitioner's opinion and interpretation, the proposed "divergent-convergent diamond structure" has the potential to make postgraduate classes more engaging. The proposed structure may suggestively promote self-efficacy, trigger curious minds, bring relevance, indulge participatory learning and consolidate the concepts.
\end{abstract}

Keywords Class inclusion, Innovative learning, Teaching pedagogy, Young adult learners

Paper type Viewpoint

Every class is a script

The curtain raises - The movie begins -

In-between the magic,

Trance dominates

Knowledge is absorbed

The curtain draws - the script ends

"Every magic trick consists of three parts or acts. First part is called the Pledge [...] the second act is called the Turn...that is not enough where the magician takes the ordinary something to do extraordinary, where making something disappear is isn't enough. You have to bring it back; every magic trick has the third act, the hardest part, Prestige". (Thomas et al., 2006)

\section{Introduction}

Quite perceptive as the opening lines of the Chistopher Nolan directed Prestige (2006), is a retelling of the Victorian magicians' film, Ilusionist, a cinematic tale of gothic century mumbo-

(C) Rima Namhata and Vinit Ghosh. Published in Vilakshan - XIMB Journal of Management. Published by Emerald Publishing Limited. This article is published under the Creative Commons Attribution (CC BY 4.0) licence. Anyone may reproduce, distribute, translate and create derivative works of this article (for both commercial and non-commercial purposes), subject to full attribution to the original publication and authors. The full terms of this licence maybe seen at http://creativecommons.org/licences/by/4.0/legalcode 
$\mathrm{XJM}$

$17,1 / 2$

jumbo. The third stage of any magic trick is the Prestige, with the first and the second stages being the Pledge and the Turn. The movie plays out with a magnificent magic trick, with the audience waiting to see how it unfolds, absorbed in the feeling, sitting through engaged, only to discover how everything will be unveiled and resolved. The entire concept reinforces on how magic works and the same idea is taken for a learner-centric teaching engagement. Teaching young adult learners in a classroom has increasingly become a challenge for the instructors; more so with the IT tools in our very existence. This viewpoint proposes a class orchestration, analogically drawing a reference from the movie, Prestige (2006). The generation of post-millennials have shorter attention span and motivation, and thus, this essay attempts to mitigate such challenges by bringing an analogy with a magic trick. The viewpoint also proposes a "Divergent-Convergent diamond structure" to anchor and synthesise teaching deliverables for the learners.

\section{The intelligent orchestration through "divergence-convergence diamond structure"}

The first two opening paragraphs set the tone of this writing towards the classroom teaching experience catering to young adult learners. This idea of delivering concepts has stemmed from our experiences in teaching postgraduate management students. Interestingly, these students are the generation of post-millennials, often used interchangeably with Generation Z or iGeneration, who are born after 1997. Teaching this generation has its peculiarities and challenges that find relevance from a Huffington Post article telling about "How technology is warping Your Memory?" Excessive reliance on technology and connectivity have found the memories of the post-millennials to be rapidly degenerating. Routine multitasking behaviour (Frand et al., 2000) have shortened attention span resulting in lack of introspection and critical thinking skills (Murray, 2004). Further, this is compounded by stress and lack of sleep, cumulatively resulting in forgetfulness. Events such as "exams, papers, grading and deadlines, are common in education for students and professors, [however] prolonged stress, perceived and reported by Gen Z, has a critical impact on learning and memory processes that are central to educational systems" (Hobson, 2019). This requires additional support system, that may include "learning design and teaching strategies", to help this generation of learners. Further, excessive dependence on technology has "atomise [d] knowledge into pieces that do not have a home in a larger conceptual framework", writes Harvard Physics professor John Edward Huth (2013). This sets the requirement for the post-millenials to connect the smaller bites of information in a larger framework often exemplified over the Baker-Baker paradox [1]. This gap engenders the role of the teacher to orchestrate like a magician in the class, which has been discussed in the following paragraphs.

The larger framework also necessitates looking at the learning aspects of the postmillennials. Studies suggest that teaching digital natives should be learner-centric instead of teacher-centric, unlike teaching the baby-boomers and the millennials. A compiled booklength committee report titled, How People Learn II: Learners, Contexts and Cultures (National Academies of Sciences, Engineering and Medicine, 2018) identifies ways to engage and empower learners. The council advocates "schools and classrooms to be "learnercentered' places, where educators pay attention to learners' attitudes and expectations about learning”.

Recent literature suggests that accomplishments of learning of students are primarily dependent on the "level of their engagement in communication and collaboration with their peers and instructors" (Serdyukov and Sistek-Chandler, 2015, p. 118). Class inclusion strategy corroborates studies of educational scholars that "Engagement is the 
amalgamation of a number of distinct elements including active learning, collaborative learning, participation, communication among teachers and students [where] students feel legitimated and supported." (Beer et al., 2010, p. 76, cited in Serdyukov and Sistek-Chandler, 2019, p. 118). This also adds to the tone of some factors "influenc[ing] the learning motivation of university students, including their socio-demographic characteristics, their academic background and the learning and teaching environment in which they evolved" (Lambert-Le Mener, 2012; Tinto, 1997, cited in Tremblay-Wragg et al., 2019, p. 2). Talking about the learning and teaching environment, a teacher can exercise some control and teaching strategies being one of them to keep the motivation alive.

Further, not only learning environments contribute to the impact of indirect learning, IT tools such as networked devices and laptops also transform learning. However, it also has a dark side that triggers erroneous distractions, when such devices are used during class hours for anything unrelated to the instructional content (such as instant messaging or playing online games). The psychological underpinning over here is the lack of motivation. The literature on teaching university students shows that a person's motivation is moderated by various environmental, individual and situational factors (Bourgeois, 2009; Eccles and Wigfield, 2002; Lazowski and Hulleman, 2016, cited in Tremblay-Wragg et al., 2019). However, in a higher education setting, certain contextual elements are likely to affect students' motivation. The critical importance of the classroom context governs the motivation level of students' learning (Viau, 2009, cited in Tremblay-Wragg et al., 2019).

Young adult learners also look for an informal yet relevant teaching from the teacher. This relevance may find meaning in the concept of enchantment such as being "caught up and carried away" through "spellbound, [and] heightened senses" (McCarthy and Wright, 2003). This can be the "moment of pure presence" which students may feel sooner they enter the classroom (Fisher, 1998). Contextualising smaller pieces of information in a broader framework, holding on to the attention span of the learners over relevant, informal and motivational nuggets appropriate orchestrating the class. This exercise induces a novel situation where the teacher brings wizardry to enhance the sensory engagement to absorb learning.

A teacher's Class [2] (to be read as lecture) is an involved and an intricate machine woven for the simple purpose of diversion. It induces concepts through higher-order learning, remembering and application of ideas. Written in italics simply to convey the show (the class) as an act of departure such as a non-linear narrative that models the ways of a magician. This writing is a tabula-rasa [3] developed over teaching experiences on Post Graduate Management students. Nonetheless, the legacy can be carried forward to all teaching methods, specifically with young adult learners. The teaching experience views in creating a mind-bending montage at every turn that unsettles the mind and keeps the audience want for more. No pretence, no perception, no memory, just intensifying the spell, without giving anything away, yet never stopping turning the tables on the audience (learners) can strengthen the genesis of every Class.

There is a prologue to every movie. There is a wizardry in every class. The magician builds up stories to create the trance for his/her audience, take them into confidence and heighten it to a level of surprise, which seems magic. This is exactly built up in certain stages of the class caricature. It is the artfulness of the magician which a teacher enacts to create the surprise element. The teacher resonates like an engineer behind the scenes who design elaborate apparatuses solely for the stage performance (here class performance). It brings the 'puzzle-like structure, scattering clues' into effect within the class design (Scott, 2006). It is more to take the mind into a trance to absorb learning, implicit learning and the entire class-design is process-driven. The apparatuses can range somewhere from a camera, 
$\mathrm{XJM}$

$17,1 / 2$

\section{2}

chairs, tables, table-chair arrangements, charts, photos, cue-cards, fish-bowl and disciplinespecific arrangements. Aligned to this process, the writers view the class as rolling from applied divergent thinking, in confluence with elaborate apparatuses, where the concepts blend into convergent learning.

To simplify this, the process of divergence to convergence has been mapped over a diamond structure and the model is explicated below (Figure 1).

A class may begin with the teacher introducing a new topic and the teacher may allow "free-thinking" in the class to trigger the curious minds. This can be the first act that corroborates to the "Pledge" of the magician. It helps to raise questions or clear any inhibitions from the learner's mind regarding the subject to be taught. Without digressing from the core, the teacher may apply "divergent thinking" techniques such as brainstorming, metanarrative, fable, story-telling, scenario planning and role-plays to engage the class. Class inclusion which represents the participation of any young learners and making them realise that their views, opinions or suggestions are valued and respected, is a fundamental part of effective teaching and caters to the idea of maintaining the self-esteem of the learners. The teacher may use examples that associate the topic's relevance with any past or current business, social or other affairs. It is essential to bring intelligent "humour" while citing examples as it is a critical part of building a climate of inclusion in the class. This inclusion assumingly enhances the impact of the applied diversion techniques, bolsters self-esteem, makes it informal, yet relevant, may enact the second act or the "turn" of the class. However, the class orchestration does not end over here.

After completion of the second act, begins the third act of the show. It is here the journey of the convergence begins with the prestige of the show. In this stage, all the ideas (theories, constructs, opinions and suggestions) converge into a unified whole. The teacher aims in applying certain checks (social, economic, environmental, legal or political) where the selective ideas (concepts) can be re-discussed and theories or learnings get reinforced. This focussed classroom discussion can accompany critical thinking tools such as case studies, analysis of reports and utility analysis. The teacher may focus on reaching a consensus; however, it is not a necessary condition. The whiteboard/blackboard must capture the entire 60-70 minutes' lecture snippets which will help a learner to revisit certain areas after the teacher has left the class.

Figure 1.

Divergent-convergent diamond structure
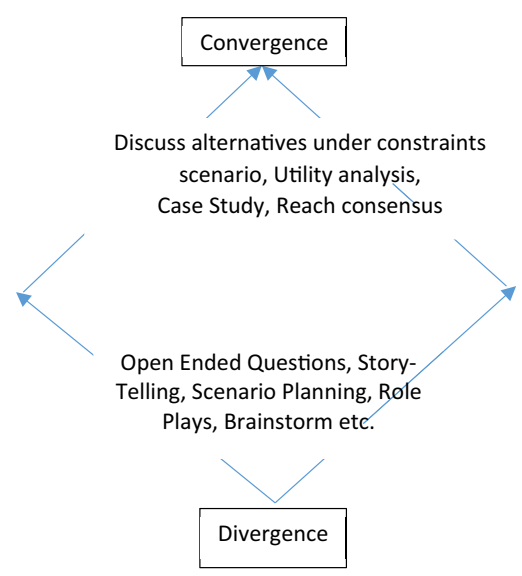
Application of "convergent-divergent" structure in the COVID times

Given to the COVID times, the teaching-learning process has undergone a shift. This essay has attempted learner-centric, virtual class engagement. The literature on online teaching suggests that a skilled online instructor considers the "social nature" of the classroom and how it can be made learner-centric. This notion contributes to the application and promotion of student interactivity (Varvel, 2006, cited in Serdyukov and Sistek-Chandler, 2015).

Virtual class precedes with an extremely detailed and clear set of instructions by the instructors. This may not resonate completely with the brick-and-mortar classroom engagement. However, keeping in mind a futuristic direction of online teaching and embracing blended learning modes, some online tools can be applied to the same model. A teacher may announce a new topic and anchor the session in the breakout rooms of Zoom [4], to allow "free-thinking" for each student to present an idea, select the best idea and discuss it in the main room of Zoom. This may be the Pledge of the Act. Divergent thinking techniques such as youtube videos, Vimeo, Tedx talks, polls (Multiple Choice Questions), interactive presentations over Mentimeter.com (concept building over word cloud), Prezi or even VideoScribe may act as class inclusion where participants' views, suggestions, critical reflection come into play. Participatory engagement through online games likes "Florence" or even "Stanley Parable" have story-telling, character-building and decision-making elements and may enact the "Turn" of the class (Cohen, 2020). These are generally called the clickers (Teaching with Technology, 2020, Berkley Resource centre for Graduate Student Instructor). The journey of convergence begins with the third act or the prestige of the online class. This can continue to consolidate concepts over Discussion forums in Learning Management System (or forums with Synchronous and asynchronous communication), a second poll or even knowledge checks over video case studies. This may act as the Prestige of the class engagement. The point of convergence or consolidating the concepts may even take recourse to the application "Audacity", where students record concepts and send them for feedback to the instructor.

Apart from motivation as a teaching-learning strategy (Ménard, 2012), other factors such as: "quality of course content, feedback and classroom management equally contributes to strategy diversification on student motivation to learn" (Iipinge, 2013; Kyndt et al., 2014; Ménard, 2012, cited in Tremblay-Wragg et al., 2019, p. 3). When the momentum of online education has already set in, academicians are still indecisive on the ways to evaluate learners. The sophisticated online platforms provide reports that effectively capture learners' reaction metrics such as "number of students enrolled", "time to complete an assignment/quiz" and "time spent on digital activities". To evaluate the degree of students' learning comprehension, pre and post online tests can be conducted. Integrated online rubricbased evaluation and feedback system may help instructors to manage the entire process of virtual classroom learning evaluation effectively. Further, proctored examinations can be conducted to maintain the sanctity of online examination. This corroborates the literature on four main classroom factors for students' motivation to learn:

(1) personal and professional qualities of the teacher;

(2) evaluative practices;

(3) classroom atmosphere; and

(4) rewards and sanctions. (Ames, 1992; Brophy, 2004; Bru, 1991; Ménard, 2012; Tinto, 2012, cited in Tremblay-Wragg et al., 2019, p. 3).

Further, instructors may create a real-life demo/Capstone project with a job-checklist assigned to the learners to check their learning outcomes.

\section{Teaching young adult learners}


$\mathrm{XJM}$

$17,1 / 2$

\section{Implications}

A learner-centric teaching style has been proposed to address the deficit attention span of young adult learners and maintain cohesive classroom engagement through a "Divergent-Convergent diamond structure". The structure attempts to make the classroom much more engaging from a practitioner's point of view to apply divergent techniques of fable, story-telling and scenario planning to build a trance. Next, class inclusion is administered to bolster self-esteem and build relevance. The proposed structure may suggestively promote self-efficacy, trigger curious minds, bring relevance, indulge participatory learning and consolidate the concepts - orchestrated over the fine blend of arts and science in imparting the learning. The commentary is unique, as partly it undertakes the journey of class teaching experience of young adult learners. This viewpoint may act as a catalyst for college instructional practices, catering to young minds, holding attention span, ensuring relevance, strengthening class inclusion, activating intelligent humour and converging the concepts. As an extension to online instruction and class engagement, the magic acts may not resonate entirely in an online platform and literature in the preceding paragraph supports the same.

\section{Conclusion}

"The trick is told, when the trick is sold". Rightly expressed, "The point of a magic trick, after all, is not the content, whatever that might be, but the ingenuity of its conceit and the skill of its execution" (Scott, 2006). This writing attempts to address the philosophy of young adult education where teachers appreciate adjustments and cater to a diverse community of young adult learners. The "Divergent-Convergent diamond structure" may be catalytic to promote selfefficacy, trigger curious minds, bring relevance, indulge participatory learning and consolidate the concepts taught with clarity. Prestige, as the title ascertains is a magician's term to refer to the art of a "climactic surprise" that a successful show manifests. The "nuts and bolts of illusionism" may keep the learners hooked to the teaching session, where divergence seamlessly weaves to the point of convergence; all orchestrated within the teacher's class design.

\section{Notes}

1. This is an experiment where respondents were divided into two groups. They were shown a picture of a man. The first group was told the last name of the man in the picture as Baker. The second group was told about the man's profession, a Baker. After some time, the groups were again shown the picture of the man and was asked to remember the associated word. It was found that those who were told about the man's profession were more likely to remember the associated word. This talks about how we contextualise images we form closely; over here (aprons, cake, oven, bread) that talks of a story, while the name Baker is independent of any broader context.

2. The authors use italics for emphasis.

3. Tabula Rasa: A Latin phrase meaning "clean slate" in English. It simply refers to knowledge that comes from experience and perception.

4. Zoom is a video conferencing and web conferencing interactive platform.

\section{References}

Cohen, J. (2020), available at: https://in.pcmag.com/gaming/68832/the-25-best-interactive-story-games

Fisher, P. (1998), Wonder, the Rainbow, and the Aesthetics of Rare Experiences, Harvard University Press. 
Frand, J., Hagner, P.R., Bates, T., Natalicio, D., Smith, K.M. and Gunderson, M. (2000), "The information-age mindset", EDUCAUSE Review, Vol. 35 No. 5, pp. 16-24.

Hobson, M.F. (2019), “\#neurominute- neuro-education and gen Z”, available at: www.snhu.edu/aboutus/newsroom/2019/10/neurominute-forming-a-memory-meet-gen-z

Huth, J.E. (2013), "Losing our way in the world”, available at: www.nytimes.com/2013/07/21/opinion/ sunday/losing-our-way-in-the-world.html

McCarthy, J.C. and Wright, P.C. (2003), "The enchantments of technology", in Blythe, M., et al. (Eds), Funology: From Usability to Enjoyment, Springer, Dordrecht, pp. 81-90.

Murray, J.P. (2004), "Nursing: the next generation”, Nursing Education Perspectives, Vol. 25 No. 3, p. 106.

National Academies of Sciences, Engineering and Medicine (2018), "How people learn II: learners, contexts, and cultures", Consensus study report, The National Academies Press, Washington, DC.

Scott, A.O. (2006), "Two rival magicians, and each wants the other to go poof", available at: www. nytimes.com/2006/10/20/movies/two-rival-magicians-and-each-wants-the-other-to-go-poof.html

Serdyukov, P. and Sistek-Chandler, C. (2015), "Communication, collaboration and relationships in the online college class: Instructors' perceptions", Journal of Research in Innovative Teaching, Vol. 8 No. 1, pp. 116-131.

Teaching with Technology (2020), available at: https:/gsi.berkeley.edu/gsi-guide-contents/technologyintro/

Thomas, E., Ryder, A. and Nolan, C. (Producers, Director) (2006), “The prestige”, [Motion Picture], Warner Bros. Pictures.

Tremblay-Wragg, É., Raby, C., Ménard, L. and Plante, I. (2019), "The use of diversified teaching strategies by four university teachers: what contribution to their students' learning motivation?", Teaching in Higher Education, pp. 1-18, doi: 10.1080/13562517.2019.1636221.

\begin{abstract}
About the authors
Rima Namhata is serving as an Assistant Professor in Jaipuria Institute of Management, Jaipur. She completed her $\mathrm{PhD}$ from IIT Kharagpur. Her research areas are Indian Campus fiction, Discourse Analysis and pedagogical approaches to Soft Skills. Her areas of interest include Business Communication, Soft Skills and Sustainability practices over Language Awareness. She has served in the capacity of Assistant Professor both in teaching UG and PG courses for the past seven years. Rima Namhata is the corresponding author and can be contacted at: rimanamhata@gmail.com

Vinit Ghosh is currently working as an Assistant Professor at Goa Institute of Management. He has completed his $\mathrm{PhD}$ in the area of Organisational Behaviour/Human Resource from Indian Institute of Technology, Guwahati. He is a BTech in Information Technology and completed his master's in Human Resource and Organisational Management. Vinit has worked eight years in various multinational IT firms such as Cognizant Technology Solutions and HCL Technologies as a business process management consultant.
\end{abstract}

For instructions on how to order reprints of this article, please visit our website:

www.emeraldgrouppublishing.com/licensing/reprints.htm

Or contact us for further details: permissions@emeraldinsight.com 